\title{
Optimum Waveforms for Differential Ion Mobility Spectrometry (FAIMS)
}

\author{
Alexandre A. Shvartsburg and Richard D. Smith \\ Biological Sciences Division, Pacific Northwest National Laboratory, Richland, Washington, USA
}

Differential mobility spectrometry or field asymmetric waveform ion mobility spectrometry (FAIMS) is a new tool for separation and identification of gas-phase ions, particularly in conjunction with mass spectrometry. In FAIMS, ions are filtered by the difference between mobilities in gases $(K)$ at high and low electric field intensity $(E)$ using asymmetric waveforms. An infinite number of possible waveform profiles make maximizing the performance within engineering constraints a major issue for FAIMS technology refinement. Earlier optimizations assumed the non-constant component of mobility to scale as $E^{2}$, producing the same result for all ions. Here we show that the optimum profiles are defined by the full series expansion of $K(E)$ that includes terms beyond the first that is proportional to $E^{2}$. For many ion/gas pairs, the first two terms have different signs, and the optimum profiles at sufficiently high $E$ in FAIMS may differ substantially from those previously reported, improving the resolving power by up to 2.2 times. This situation arises for some ions in all FAIMS systems, but becomes more common in recent miniaturized devices that employ higher $E$. With realistic $K(E)$ dependences, the maximum waveform amplitude is not necessarily optimum, and reducing it by up to $\sim 20 \%$ to $30 \%$ is beneficial in some cases. The present findings are particularly relevant to targeted analyses where separation depends on the difference between $K(E)$ functions for specific ions. (J Am Soc Mass Spectrom 2008, 19, 1286-1295) @ 2008 American Society for Mass Spectrometry

$\mathrm{D}$ ifferential ion mobility spectrometry (DMS) is becoming a powerful method of broad utility for analysis of gas-phase ions and separation of their mixtures [1-5]. The introduction of commercial DMS instruments and particularly their integration with mass spectrometry (MS) and/or liquid or gas chromatography since 2003 has enabled rapid growth of the number and diversity of applications that include environmental analyses [6, 7], food and water quality assurance [8-10], bacterial typing [11, 12], forensic investigations [13], proteomics and metabolomics [1417], pharmaceutical studies [18-20], and protein folding research [21-25]. Since its earliest days, DMS has been employed to detect explosives, drugs, and chemical warfare agents, and its role in defense, security, and law enforcement settings continues expanding [26-31].

As captured by the name, DMS separates ions based on the difference between their mobilities $(K)$ at high and relatively low electric field intensity $(E)[1,5]$. The mobility of any ion depends on $E$ and the gas number density $(N)$, and we can expand $K(E / N)$ in a series [7, 30, 32, 33]:

$$
K(E / N)=K(0)[1+a(E / N)]=K(0)\left[1+\sum_{n=1}^{\infty} a_{n}(E / N)^{2 n}\right]
$$

Address reprint requests to Dr. R. D. Smith, Biological Sciences Division, Pacific Northwest National Laboratory, 3335 Q Ave. (K8-98), P.O. Box 999, Richland, WA 99352, USA. E-mail: rds@pnl.gov where $a$ is the relative deviation of $K$ from its low-field limit $K(0)$. The $a_{\mathrm{n}}$ coefficients are functions of the ion-gas molecule potential [32] and can produce $a>0$ or $a<0$, depending on their values and $E / N$. In principle, one can deduce $a$ for any ion from measurements of $K$ at different $E / N$ using drift tube ion mobility spectrometry (DT IMS) [32, 34-36]. However, that approach does not permit separating ion mixtures based on the difference, and thus is of limited analytical utility. Also, for larger polyatomic and biomolecular ions that are of most interest, the $a(E / N)$ dependence is usually weak. For $E / N$ allowed by the electrical breakdown limitations of gases at standard temperature and pressure (STP), typical $|a|$ are $\sim 10^{-2}$ (except for the smallest ions) [37]. That is close to the accuracy of existing DT IMS systems, and $K(E / N)$ for sizable ions such as peptides appear flat [38].

In DMS, $a(E / N)$ is elicited directly using a periodic time-dependent electric field $E(t)$ that comprises short segments $E_{+}(t)$ with high $E$ and longer segments $E_{-}(t)$ with lower $E$ of opposite polarity such that mean $E$ over the period $t_{\mathrm{c}}$ is null (the zero-offset condition) [33, 39-43]:

$$
\bar{E}=\frac{1}{t_{c}} \int_{0}^{t_{c}} E(t) d t=0
$$

but absolute $\bar{E}_{+}(t)$ and $\bar{E}_{-}(t)$ differ. It is convenient to normalize $E(t)$ as 


$$
E(t)=E_{D} F(t)
$$

where $E_{\mathrm{D}}$ is the peak absolute amplitude ("dispersion field") and $F(t)$ defines the functional form. The condition of $F(t)$ asymmetry is:

$$
\left\langle F_{2 n+1}\right\rangle=\frac{1}{t_{c}} \int_{0}^{t_{c}} F^{2 n+1}(t) d t \neq 0
$$

for at least one $n \geq 1$. In earlier treatises [33, 39-43], this inequality was stipulated for $n=1$ or all $n \geq 1$. Either condition is sufficient though not necessary, as expression 4 may equal 0 for $n=1$ but not some greater $n$. Current DMS methods mainly utilize $n=1$, but higherorder separations based on $n \geq 2$ are feasible [44]. The quantity $\left\langle F_{3}\right\rangle$ characterizing the waveform is known as the "form-factor" [45], and $\left\langle F_{2 n+1}\right\rangle$ may be viewed as form-factors of various orders.

The asymmetry of $E(t)$ gave raise to the other name for DMS-field asymmetric waveform IMS, or FAIMS. Ions with $a=0$ would oscillate in such field without separation. In reality, the displacements during $E_{+}(t)$ and $E_{-}(t)$ do not cancel fully: ions drift in the direction of $E_{+}(t)$ segment when $a($ high $E)>a($ low $E)$ and $E_{-}(t)$ otherwise. The net displacement over the cycle is:

$$
d=\int_{0}^{t_{c}} K(E / N) E(t) d t
$$

To employ this mechanism for spatial dispersion of ions based on $a(E / N)$, one needs a field of $>\sim 60 \mathrm{Td}$ (or $\sim 15$ $\mathrm{kV} / \mathrm{cm}$ at STP) over large distances. That being impractical, FAIMS is implemented as a filtering method using a constant weak "compensation field" $E_{C}$ superposed on $E(t)$. A certain $E_{\mathrm{C}}$ of approximately:

$$
E_{C}=d /\left(K t_{c}\right)
$$

offsets the net drift due to $E(t)$ for a particular species, while others with different $a(E / N)$ still migrate along the $E_{C}$ axis. The $\left\{E(t)+E_{C}\right\}$ field is maintained in a gap between two electrodes carrying $\mathrm{rf}$ and dc voltages. This allows the species with correct $E_{\mathrm{C}}$ to stay balanced and pass the gap to be detected, while others move toward an electrode and are neutralized. As with other filtering techniques, such as quadrupole MS, one can fix $E_{C}$ to monitor selected ions or scan $E_{C}$ to reveal the spectrum of species present.

Numerous asymmetric $F(t)$ comply with eq 2; one comprises two rectangles $[33,39,40,45,46]$ :

$$
\begin{aligned}
& F=1 \text { for } t=\left[0 ; t_{c} /(f+1)\right] ; F=-1 / f \\
& \quad \text { for } t=\left[t_{c} /(f+1) ; t_{c}\right]
\end{aligned}
$$

where $f>1$ (Figure 1a, Figure 2). The number of possible $F(t)$ is infinite even within eq 7, but not limited to it. For example, two right scalene triangles (Figure

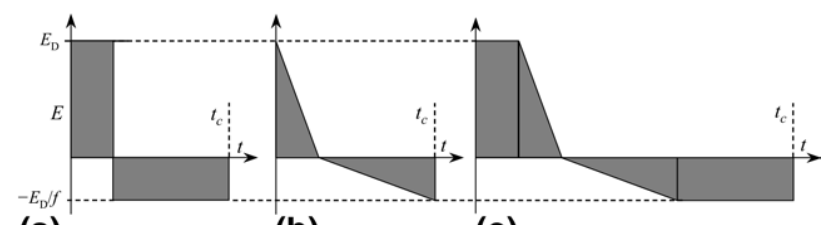

(a)

(b)

(c)

Figure 1. Asymmetric waveforms: rectangular (a), triangular (b), and trapezoidal (c).

$1 b)$ would do. As the integral of a sum equals the sum of integrals, any sequence of $F(t)$ satisfying eqs 2 and 5 that remains asymmetric will also work, e.g., a trapezoidal (Figure 1c) built from rectangles and triangles.

To find the best $F(t)$ for FAIMS analyses, we need to define the optimization criterion. In general, the electric field in FAIMS may not just separate different ions but also focus them to the gap median, reducing losses to electrodes $[5,46]$. Focusing requires inhomogeneous field created in gaps of curved (e.g., cylindrical or spherical) shape. In planar geometries, homogeneous field permits no focusing. While focusing improves ion transmission through FAIMS, it introduces discrimination based on $a(E / N)$ and limits the resolving power $R$ by rendering ions with multiple $E_{C}$ stable in the gap. For low ion currents, the disadvantages outweigh gains and the overall performance (quantified via the resolution/sensitivity diagrams) maximizes for planar gaps [4]. This study formally addresses planar FAIMS, but the conclusions should extend to all geometries. In the absence of focusing, the electric field affects separation only and the $F(t)$ providing best separation is optimum. In global analyses, that means the maximum of $R$ normally defined as the absolute separation parameter (here $E_{\mathrm{C}}$ ) divided by the full peak width at half maximum, $w_{1 / 2}$ :

$$
R=\left|E_{C}\right| / w_{12}
$$

In targeted analyses, the resolution of specific features (e.g., $\mathrm{X}$ and $\mathrm{Y}$ ) is characterized by

$$
r=2\left[\left|E_{C}(X)-E_{C}(Y)\right|\right] /\left[w_{12}(X)+w_{12}(Y)\right]
$$

This metric may be extended to three or more species.

Previous efforts to optimize FAIMS waveforms [33, $39,40,45]$ sought to maximize $\left|E_{C}\right|$ rather than $R$, i.e., a constant $w_{1 / 2}$ was implied. While the choice of $F(t)$ affects the average $E / N$ in FAIMS, and thus the average diffusion that determines the peak width [32, 47], the effect on $E_{C}$ is much stronger, and fixing $w_{1 / 2}$ is a fair approximation that we follow in this work. By eqs 5 and 6 , maximizing $\left|E_{C}\right|$ means maximizing $|d|$. Introducing the reduced mobility $K_{0}=K N / N_{0}$ (where $N_{0}$ is $N$ at STP) and combining eqs 1 to 5 , one obtains:

$$
d=K_{0}(0)\left(E_{D} / N\right) t_{c} \sum_{n=1}^{\infty} a_{n}\left(E_{D} / N\right)^{2 n}\left\langle F_{2 n+1}\right\rangle
$$

For any $a_{\mathrm{n}}$ set, $d$ depends on the $\left\langle F_{2 n+1}\right\rangle$ values for specific $F(t)$. 


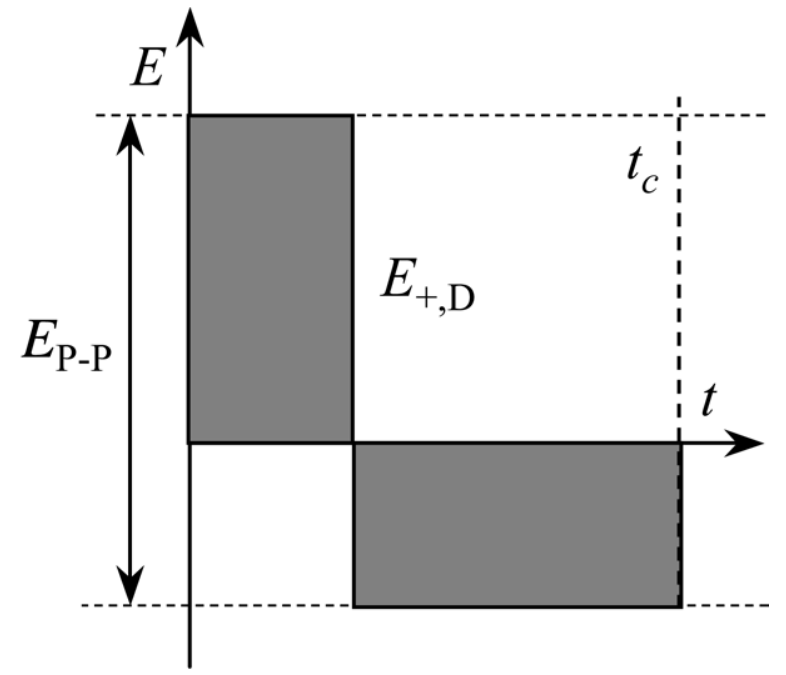

(a)

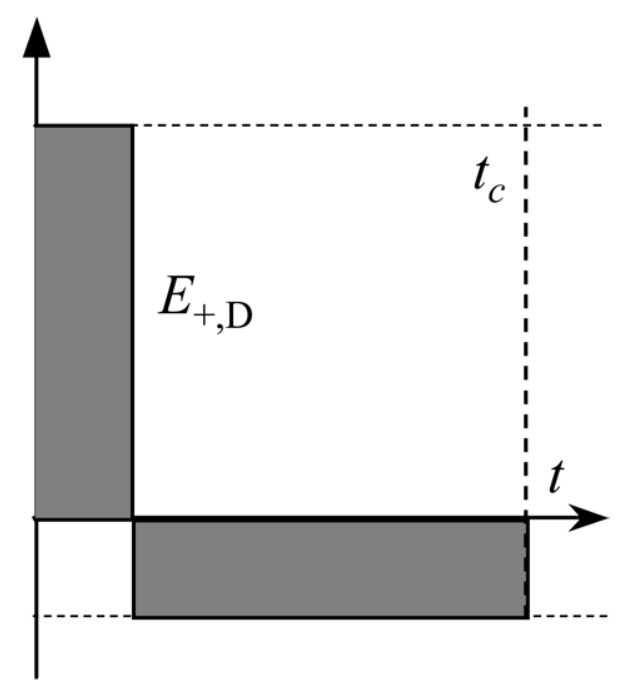

(b)

(c)

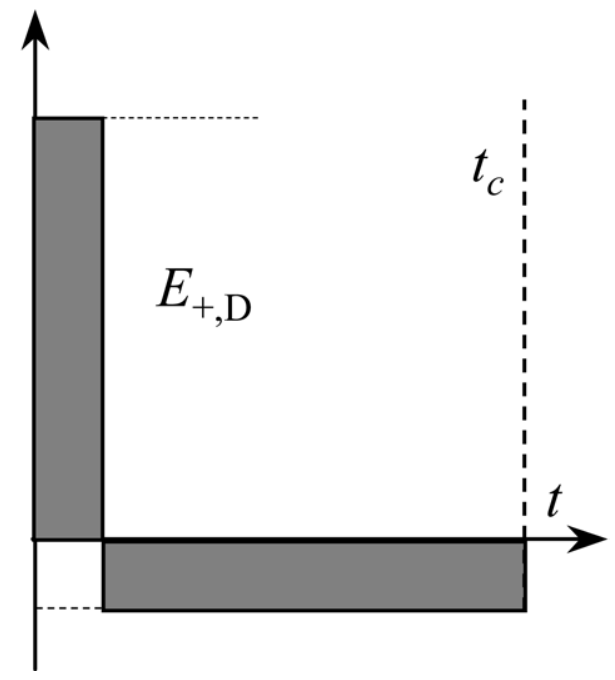

Figure 2. Rectangular waveforms with fixed peak-to-peak amplitude have greater peak amplitudes at higher $f$ : profiles with $f=$ 2 (a), 4 (b), and 6 (c).

Earlier $F(t)$ optimizations [33, 39, 40, 45] have represented $a(E / N)$ by the leading $(n=1)$ term of eq 1 that commonly dominates the separation in "full-size" FAIMS systems [5] operated at $E / N<\sim 100 \mathrm{Td}$. However, terms with $n \geq 2$ are often important even here and grow quickly at higher $E / N$, becoming dominant at $>120 \mathrm{Td}$ employed in latest miniaturized $[3,7,48]$ and reduced-pressure [49] FAIMS devices. Also, the $E(t)$ profiles were optimized for fixed peak $\left(E_{\mathrm{D}}\right)$ or peak-topeak $\left(E_{\mathrm{P}-\mathrm{P}}\right)$ amplitude, implying the maximum possible amplitude to be best. Here we show that lowering $E_{\mathrm{D}}$ or $E_{\mathrm{P}-\mathrm{P}}$ may improve separation, hence both the waveform profile and amplitude must be optimized. This is done here for realistic $a(E / N)$ functions.

\section{Global Waveform Optimization}

The rectangular $F(t)$ by eq 7 is called "ideal" as it maximizes $|d|$ and thus FAIMS resolution. This happens because $E$ in $E_{+}(t)$ and $E_{-}(t)$ is fixed, while other forms comprise a range of $E$ in either or both and hence are less asymmetric. Then:

$$
\left\langle F_{2 n+1}\right\rangle=\left(1-f^{-2 n}\right) /(f+1)
$$

All $\left\langle F_{2 n+1}\right\rangle$ by eq 11 and thus $d$ by eq 10 are trivially null for $f=1$ when $F(t)$ is symmetric and $f \Rightarrow \infty$ when $F=0$. Hence $|d|$ reaches maximum $\left(d_{\max }\right)$ at an intermediate $f$, with the optimum $\left(f_{\text {opt }}\right)$ depending on $E_{\mathrm{D}} / N$ and relative $a_{\mathrm{n}}$ values. For the leading term of eq 10:

$$
\left\langle F_{3}\right\rangle=(f-1) / f^{2},
$$

that reaches the maximum absolute $\left\langle F_{3}\right\rangle$, or $\left\langle F_{3}\right\rangle_{\max }$, of $1 / 4$ at [39] $f_{\mathrm{opt}}=2$. The maximum is not abrupt, particularly on the high- $f$ side: e.g., the $\left\langle F_{3}\right\rangle$ value is below $\left\langle F_{3}\right\rangle_{\max }$ by $\approx 11 \%$ at $f=1.5$ or $f=3$ and $25 \%$ at $f=$ 4 (Figure 3a). This allows other effects to greatly shift $f_{\text {opt }}$, as discussed below.

This optimization assumed constant $E_{\mathrm{D}}$, which is often limited by the electrical breakdown threshold. The optimum for rectangular $E(t)$ with fixed peak-to-peak amplitude $\left(E_{\mathrm{P}-\mathrm{P}}\right)$, that often results from engineering limitations, differs because shifting $f$ above 2 increases $E_{\mathrm{D}}$ (Figure 2), and $|d|$ initially rises despite decreasing for constant $E_{\mathrm{D}}$ and $f_{\mathrm{opt}}>2$. Indeed:

$$
E_{\mathrm{D}}=f E_{\mathrm{P}-\mathrm{P}} /(f+1)
$$

and eq 10 converts to:

$$
d=\frac{K_{0}(0) f t_{c}}{(f+1)^{2}} \frac{E_{P-P}}{N} \sum_{n} a_{n}\left(\frac{E_{P-P}}{N}\right)^{2 n} \frac{f^{2 n}-1}{(f+1)^{2 n}}
$$

The leading term of eq 14 is:

$$
d=K_{0}(0) a_{1} t_{c} \frac{f(f-1)}{(f+1)^{3}}\left(\frac{E_{P-P}}{N}\right)^{3}
$$

and $|d|$ has a (also gradual) maximum [40] at $f=$ $2+\sqrt{3} \cong 3.73$ (Figure $3 b$ ) when 

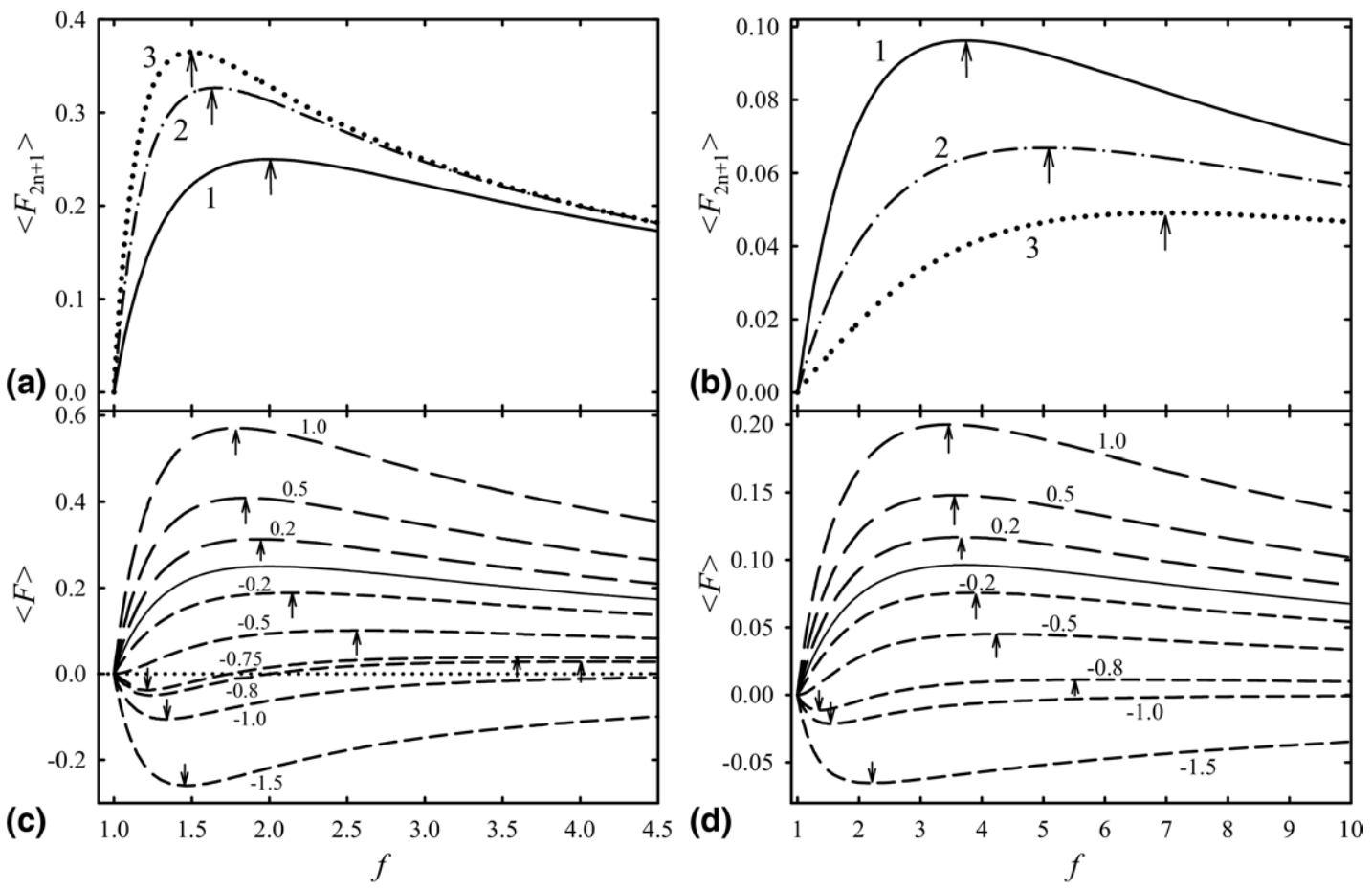

Figure 3. Form-factors of rectangular $E(t)$ constrained by $E_{\mathrm{D}}(\mathbf{a})$, (c) and $E_{\mathrm{P}-\mathrm{P}}(\mathbf{b})$, (d) for hypothetical ions with various $a_{\mathrm{n}}$ values. In (a), (b), $a_{\mathrm{n}}=1$ for $n=1-3$ as labeled and $a_{\mathrm{n}}=0$ for other $n$. In (c), (d), $a_{\mathrm{n}}=0$ for $n>2$ and $a_{\mathrm{R}}$ values are labeled, curves are for $a_{\mathrm{R}}=0$ (solid line), $a_{\mathrm{R}}>0$ (long dash), and $a_{\mathrm{R}}<0$ (short dash). The maxima are marked by arrows up, minima by arrows down. The dotted line in (c) is for $\langle F\rangle=0$ (no separation).

$$
d_{\max }=K_{0}(0)\left|a_{1}\right| t_{c} \sqrt{3}\left(E_{P-P} / N\right)^{3} / 18
$$

The trends of eqs 12 and 15 were verified by measurements [40,50], producing $f_{\text {opt }} \sim 2$ with constant $E_{\mathrm{D}}$ and $\sim 3.7$ with constant $E_{\mathrm{P}-\mathrm{P}}$. Constraints on both $E_{\mathrm{P}-\mathrm{P}}$ and $E_{\mathrm{D}}$ lead to $2<f_{\text {opt }}<3.73$.

However, accepting $f=2$ or 3.73 as the optima [33, $39,40,45,51]$ for rectangular $F(t)$ is inaccurate because the $\left\langle F_{2 n+1}\right\rangle$ quantities for $n>1$ are not null and maximize at different $f$ (Figure $3 \mathrm{a}, \mathrm{b}$; Table 1 ). With $E_{\mathrm{D}}$ constraint, $f_{\text {opt }}$ decreases for higher $n$ because the $2 n$ power over $E_{\mathrm{D}}$ magnifies the dissimilarity between $F_{+}(t)$ and $F_{-}(t)$, and the same ion motion disbalance requires a smaller difference in $E$. With the $E_{\mathrm{P}-\mathrm{P}}$ constraint, $f_{\text {opt }}$ increases for higher $n$. So $|d|$ always maximizes at $f \neq 2$ or 3.73 , unless at very low $E_{\mathrm{D}} / N$ (or for ions with unusually small $a_{\mathrm{n}}$ for $n>1$ ) where terms

Table 1. Optimum $f$ and maximum $\left\langle F_{2 n+1}\right\rangle$ values up to $n=5$ for rectangular $F(t)$

\begin{tabular}{cccccc}
\hline & \multicolumn{2}{c}{$E_{\mathrm{D}}$ fixed } & & \multicolumn{2}{c}{$E_{\mathrm{P}-\mathrm{P}}$ fixed } \\
\cline { 2 - 3 } \cline { 5 - 6 } Separation order & $f_{\mathrm{opt}}$ & $\left\langle F_{2 n+1}\right\rangle$ & & $f_{\mathrm{opt}}$ & $\left\langle F_{2 n+1}\right\rangle$ \\
\hline \hline$n=1$ & 2 & 0.250 & & 3.73 & 0.0962 \\
$n=2$ & 1.65 & 0.326 & & 5.04 & 0.0669 \\
$n=3$ & 1.49 & 0.365 & & 7.00 & 0.0491 \\
$n=4$ & 1.40 & 0.388 & & 9.00 & 0.0387 \\
$n=5$ & 1.34 & 0.404 & & 11.0 & 0.0320
\end{tabular}

with $n>1$ are negligible. As good FAIMS separations require substantial $E_{\mathrm{D}} / N$, the terms with $n=2$ are usually important and those with $n=3$ and even 4 may also be significant $[44,52]$. The present discussion is limited to $n \leq 2$, which often suffices [52] at moderate $E_{\mathrm{D}} / N(<\sim 80$ to $100 \mathrm{Td})$.

The differences between $f_{\text {opt }}$ values at $n=1$ to 4 , especially 1 and 2, are modest compared to the breadth of maxima of $\left\langle F_{2 n+1}\right\rangle(f)$ curves (Figure $3 \mathrm{a}, \mathrm{b}$ ). Hence $\left\langle F_{2 n+1}\right\rangle$ values for one $n$ are close to their maxima at $f_{\text {opt }}$ for other $n$. For example, in Figure $3 a$, the value of $\left\langle F_{5}\right\rangle$ at $f=2$ is $\sim 96 \%$ of $\left\langle F_{5}\right\rangle_{\max }$ found at $f=1.65$. However, the terms with $n>1$ matter for optimum $F(t)$ because $|d|$ may maximize outside of the range between $f_{\text {opt }}$ for specific $n$ when the signs of at least two $a_{\mathrm{n}}$ differ. With only two $n$ (e.g., 1 and 2), this happens when $a_{\mathrm{n}}$ have opposite signs. In such cases, $f_{\text {opt }}$ may greatly differ from that for $n=1$ when the ratio of $n=2$ and $n=1$ terms in eq 1 ,

$$
a_{R}=a_{2}\left(E_{\mathrm{D}} / N\right)^{2} / a_{1}
$$

is not far from -1 . For instance, at $a_{\mathrm{R}}=-0.8$ (with $E_{\mathrm{D}}$ constraint), $d_{\max }$ is located at $f \sim 1.24$, while at $f=2$ we find $d=0$, i.e., no separation occurs (Figure 3c)! This extreme example clearly shows that $n>1$ terms are crucial for waveform optimization when $a_{1}$ and $a_{2}$ have opposite signs, a common situation as discussed below. For further analysis, we parse eqs 10 and 14 as 

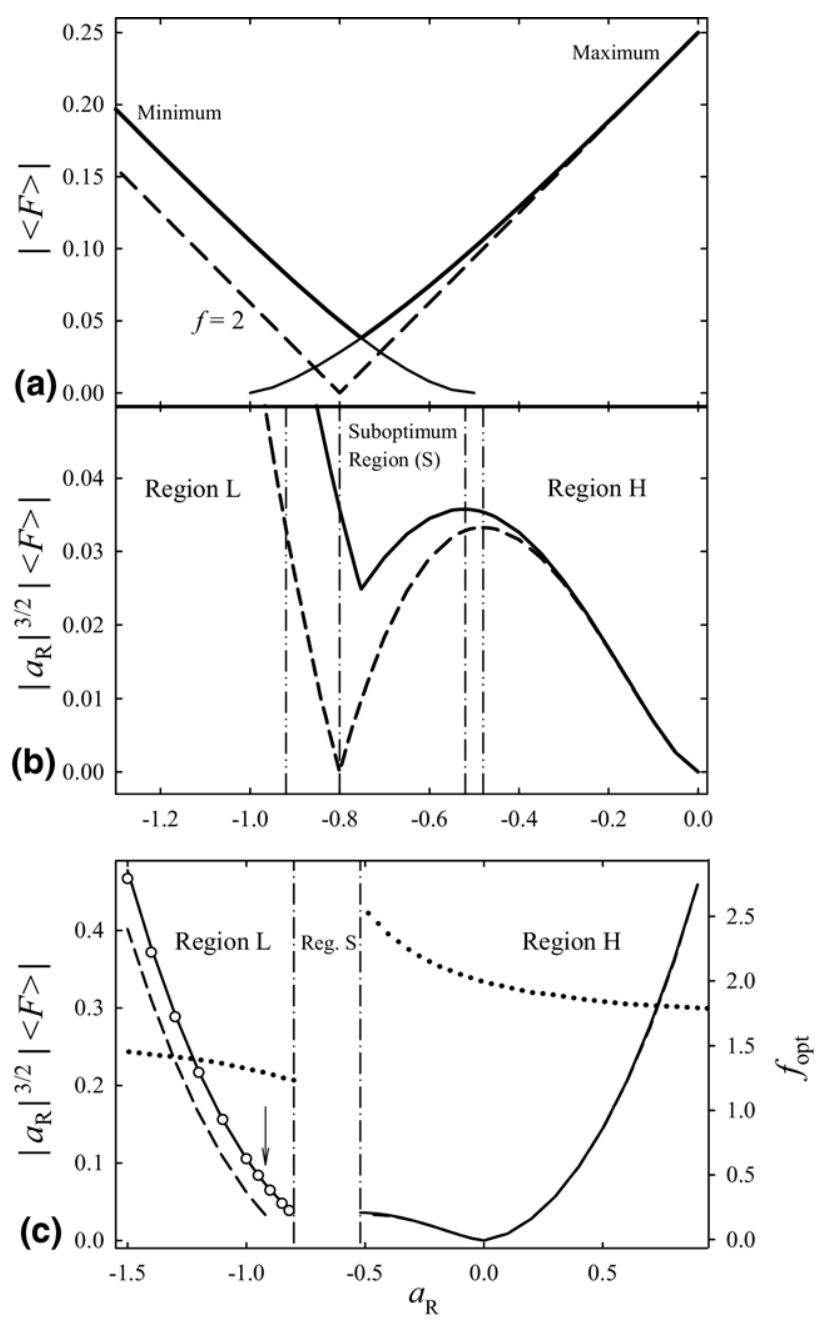

Figure 4. Properties of separations using rectangular $E(t)$ with $E_{\mathrm{D}}$ constraint: (a) absolute form-factor (derived from Figure 3c) and (b), (c) (left axis) absolute ion displacements per FAIMS cycle [in the units of $a_{1}^{5 / 2} a_{2}{ }^{-3 / 2} K_{0}(0) t_{\mathrm{c}}$ ] for fixed (b) and variable (c) $E_{\mathrm{D}}$. Thin solid lines (a) are for maximum or minimum $\langle F\rangle$ as labeled, thick solid lines are for maximum $|\langle F\rangle|$, dashed lines are for fixed $f$ as marked, and circles (c), (region L) are for $f=1.35$. Vertical lines show the region boundaries: dash-dot-dot (b) for fixed $f$ and dash-dot (b), (c) for variable $f$. In (c), the arrow points to the greatest difference between $|d|$ with optimum $f$ and $f=2$ (that is best at $a_{\mathrm{R}}=0$ ) and the dotted line shows optimum $f$ (right axis).

$$
\begin{aligned}
d= & K_{0}(0) a_{1}\left(E_{D} / N\right)^{3} t_{c}\langle F\rangle=K_{0}(0) a_{1}\left(E_{P-P} / N\right)^{3} t_{c} f^{3}\langle F\rangle / \\
& (f+1)^{3}
\end{aligned}
$$

where $\langle F\rangle$ is the "effective form-factor":

$$
\langle F\rangle=\left\langle F_{3}\right\rangle+a_{R}\left\langle F_{5}\right\rangle
$$

As the separation power depends on $\left|E_{C}\right|$ and $|d|$, what matters is absolute $\langle F\rangle$.

First, we optimize $f$ for constant $E_{\mathrm{D}}$. When $a_{1}$ and $a_{2}$ have same signs, $f_{\text {opt }}$ shifts from 2 for $n=1$ to $\cong 1.65$ for $n=2$ as $a_{\mathrm{R}}$ increases (Figure 3c); as shown above, $f=2$ is only slightly suboptimum even at highest $a_{\mathrm{R}}$. With opposite $a_{1}$ and $a_{2}$ signs, $f_{\text {opt }}$ rapidly rises with decreas- ing $a_{\mathrm{R}}$ (Figure $3 \mathrm{c}$ ) and keeping $f=2$ can drastically decrease absolute $\langle F\rangle$. For $a_{\mathrm{R}}<-0.5$, a region of $\langle F\rangle<0$ appears at $f$ near 1.0. As $a_{\mathrm{R}}$ decreases, the minimum moves to higher $f$ and deepens while the maximum lowers, and for $a_{\mathrm{R}} \cong-0.75$ the value of $|\langle F\rangle|$ in the minimum (at $f \cong 1.21$ ) reaches that in the maximum (at $f \cong 3.59$ ). Then the maximum shifts to still higher $f$ and disappears at $a_{\mathrm{R}}=-1$ and $f \Rightarrow \infty$ while the minimum further deepens and also shifts to higher $f$, approaching $\cong 1.65$ for $a_{R} \Rightarrow-\infty$ (Figure $3 \mathrm{c}$ ). Fixing $E_{\mathrm{P}-\mathrm{P}}$ instead of $E_{\mathrm{D}}$ produces similar behavior (Figure $3 \mathrm{~d}$ ), with $|\langle F\rangle|$ in the minimum and maximum equalizing for $a_{\mathrm{R}} \cong-0.85$ when $f \cong 1.46$ and $\cong 5.97$, respectively.

Similarly to the case of $f=2$, the optimum $|\langle F\rangle|$ minimizes close to $a_{\mathrm{R}}=-0.8$ (Figure $4 \mathrm{a}$ ). Unlike at $f=$ 2 , the minimum is not null and thus permits some separation, but its height is only $\sim 15 \%$ of $\left\langle F_{3}\right\rangle_{\max }$ at $a_{\mathrm{R}}=$ 0 and the resolution at $a_{\mathrm{R}}$ close to -0.8 would be poor. An analogous picture for fixed $E_{\mathrm{P}-\mathrm{P}}$ follows from Figure $3 \mathrm{~d}$. Then, reducing $\left|a_{R}\right|$ by use of below-maximum $E_{\mathrm{D}} / N$ or $E_{\mathrm{P}-\mathrm{P}} / N$ may be profitable, despite lower $(E / N)^{3}$ factors in eq 18. To optimize $E_{\mathrm{D}}$ and $F(t)$ simultaneously, we may combine eqs 17 and 18 with either $E_{D}$ or $E_{\mathrm{P}-\mathrm{P}}$ constraint into

$$
d=K_{0}(0)\left(a_{1}^{5} a_{2}^{-3} a_{R}^{3}\right)^{1 / 2} t_{c}\langle F\rangle
$$

At any given $a_{\mathrm{R}}$, the value of $|d|$ is greatest at the maxima of $|\langle F\rangle|$. For $f=2$, that value grows with decreasing $a_{\mathrm{R}}$ up to $a_{\mathrm{R}} \cong-0.48$, then drops to 0 at $a_{\mathrm{R}}=$ -0.8 , and rises again (Figure $4 \mathrm{~b}$ ). In the result, the values of $|d|$ are lower for $-0.92<a_{\mathrm{R}}<-0.48$ than for $a_{\mathrm{R}}=-0.48$. So $|d|$ can be increased by decreasing $E_{\mathrm{D}} / N$ until $a_{\mathrm{R}}=-0.48$, which means reducing $E_{\mathrm{D}}$ by up to $28 \%$. For optimum $f$, the minimum of $|d|$ becomes shallower and the suboptimum region (S) shrinks to $-0.80<a_{\mathrm{R}}<-0.52$ (Figure $4 \mathrm{~b}$ ), but maximizing $|d|$ may still require decreasing $E_{\mathrm{D}}$ by up to $19 \%$.

Hence, to maximize $\left|E_{C}\right|$, one should (Figure 4c): (1) for $a_{2}$ and $a_{1}$ with same signs, raise $E_{\mathrm{D}} / N$ to the allowed maximum while decreasing $f$ from 2 to $f \cong 1.65$ to 2.0 , depending on $E_{\mathrm{D}} / N$; (2) for $a_{2}$ and $a_{1}$ with opposite signs, raise $E_{\mathrm{D}} / N$ until $a_{\mathrm{R}}$ reaches -0.52 while increasing $f$ from 2 to $\cong 2.6$, then (if limitations on $E_{\mathrm{D}} / N$ permit) jump to $a_{\mathrm{R}}=-0.8$ and $f=1.24$ and raise $E_{\mathrm{D}} / N$ to the maximum while increasing $f$ up to 1.65 , again depending on $E_{\mathrm{D}} / N$. To enable all those capabilities, the value of $f$ must be adjustable from 1.24 to 2.6. However, the fixed $f=2$ provides $\left|E_{C}\right|$ within $7 \%$ of the maximum for $a_{\mathrm{R}}>-0.52$ and other $f$ have real worth only on the low $-a_{\mathrm{R}}$ side of region $S$ (in the following, region $\mathrm{L}$ ), especially $a_{\mathrm{R}} \sim-(0.9$ to 1.2$)$, where $f_{\text {opt }} \cong 1.3$ grossly differs from 2 and $\left|E_{C}\right|$ at $f_{\text {opt }}$ can reach 2.2 times that at $f=2$ (Figure $4 \mathrm{c}$ ). Adopting $f=2$ on the high- $a_{\mathrm{R}}$ side (region $\mathrm{H}$ ) and $f=1.35$ in region $\mathrm{L}$ provides $\left|E_{C}\right|$ within $9 \%$ of the maxima at any $a_{\mathrm{R}}$ (Figure $4 \mathrm{c}$ ) while reducing the needed waveform flexibility to switching between two $f$ values. 


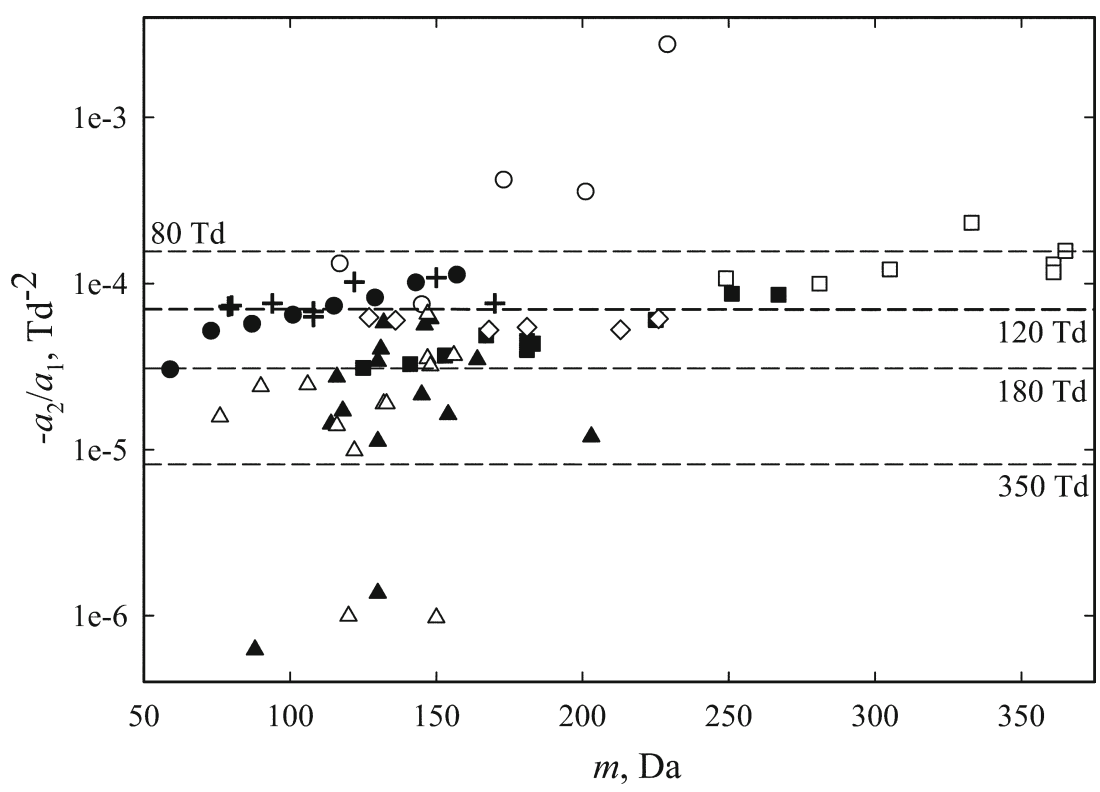

Figure 5. Measured values of $a_{2} / a_{1}$ for representative type B ions: protonated (open triangle) and deprotonated (filled triangle) amino acids [54], protonated benzene and amines (crosshair) [55], protonated ketone monomers (filled circle) and dimers (open circle) [56], protonated monomers (filled square), and dimers (open square) of organophosphorus compounds [57], and deprotonated or radical anions of explosives (open diamond) [28]. Horizontal lines mark values providing $a_{\mathrm{R}}=-1$ at the stated $E / N$.

The present optimization may be extended to $a(E / N)$ including terms with $n>2$ and/or waveforms constrained by $E_{\mathrm{P}-\mathrm{P}}$. With either constraint, the evolution of $\left\langle F_{2 n+1}\right\rangle(f)$ dependences for $n>2$ continues the trend from $n=1$ to 2 (Figure 3, Table 1). Hence the effect of adding a term with any $n>2$ to the $n=1$ term is akin to that of adding the $n=2$ term considered here, but (for equal $a_{\mathrm{n}} / a_{1}$ ratio) greater because the difference between $\left\langle F_{2 n+1}\right\rangle$ and $\left\langle F_{3}\right\rangle$ increases at higher $n$ for any $f$ value (Figure $3 \mathrm{a}, \mathrm{b}$ ). The addition of term(s) with $n>2$ to the presently studied superposition of $n=1$ and 2 terms may produce more complex dependences, which may be important at highest $E / N$ values where the terms with $n>2$ become substantial.

\section{Relevance to Actual FAIMS Measurements}

As the best waveforms of any class are determined by $a_{\mathrm{R}}$ one may wonder what values are realistic. Of particular interest are the cases of $a_{\mathrm{R}} \sim-(0.5$ to 1.5$)$ for which the optimum forms are most sensitive to $a_{\mathrm{R}}$ and notably differ from those for $a_{\mathrm{R}}=0$. The $a_{\mathrm{R}}$ for any ion/gas pair scales as
$(E / N)^{2}$ by eq 17 , hence in theory one may reach any $\left|a_{R}\right|$ at strong enough fields and the notion of a "typical" $a_{\mathrm{R}}$ makes sense only for specific $E_{\mathrm{D}} / N$ magnitude. The original "full-size" FAIMS design largely adopted in Thermo Fisher (Waltham, MA) systems features gap widths $(g)$ of $\sim 1.5$ to $2.5 \mathrm{~mm}$ and operates at ambient pressure, normally employing $E_{\mathrm{D}} \sim 15$ to $25 \mathrm{kV} / \mathrm{cm}$ or $E_{\mathrm{D}} / N \sim 60$ to $100 \mathrm{Td}$ : at weaker fields the drift nonlinearity rarely suffices for good separation while the electrical breakdown threshold precludes much stronger fields (in $\mathrm{N}_{2}$ or air) [53]. That threshold increases for narrower gaps according to the Paschen's law [53], and micromachined FAIMS devices (e.g., SDP-1 by Sionex (Bedford, MA) with $g=0.5 \mathrm{~mm}$ ) [7] allow $E / N$ up to $140 \mathrm{Td}$. Same may be achieved by reducing the gas pressure, e.g., $E / N=180 \mathrm{Td}$ was established at $\sim 390$ torr [49]. The recent development of FAIMS "chips" with $g \sim 10 \mu \mathrm{m}$ by Owlstone (Cambridge, $\mathrm{UK})$ has allowed raising $E / N$ to $\sim 400 \mathrm{Td}[48]$.

The value of $a_{\mathrm{R}}$ also depends on the ion(s) and gas through the $a_{2} / a_{1}$ ratio, and we shall now estimate those for global and targeted separations.

Table 2. Values of $a_{1}$ and $a_{2}$ for some ions in air or $\mathrm{N}_{2}$ (at $T=300 \mathrm{~K}$ ) measured using FAIMS ${ }^{\mathrm{a}}$

\begin{tabular}{llllllrrrrr}
\hline \multicolumn{1}{c}{ Species } & $\mathrm{Cl}^{-}$ & Ala & Pro & Ser & Leu & Ile & ProOH & Glu & H $^{+}($dec.) & TNT \\
\hline \hline Mass, $\mathrm{Da}$ & 35 & 88 & 114 & 104 & 130 & 130 & 130 & 146 & 157 & 226 \\
$a_{1}, 10^{-6} \mathrm{Td}^{-2}$ & 18.7 & 12.0 & 7.82 & 12.4 & 5.43 & 5.15 & 5.55 & 7.12 & 4.6 & 4.4 \\
$a_{2}, 10^{-10} \mathrm{Td}^{-4}$ & 64 & -0.075 & 0.50 & -1.77 & -1.85 & -0.58 & -0.08 & -4.0 & -5.2 & -2.7 \\
$a_{2} / a_{1}, 10^{-5} \mathrm{Td}^{-2}$ & 34 & -0.063 & 0.64 & -1.4 & -3.4 & -1.1 & -0.14 & -5.6 & -11.3 & -6.1 \\
\hline
\end{tabular}

aData are from $[47,52]$ for $\mathrm{Cl}^{-},[54]$ for deprotonated amino acids (alanine, proline, serine, leucine, isoleucine, hydroxyproline, and glutamic acid), [56] for $\mathrm{H}^{+}$(decanone), and [28] for the deprotonated TNT. 


\section{Global Separations}

In global analyses, one seeks to maximize the overall separation space, which in FAIMS means typical $\left|E_{C}\right|$ values as reviewed in the Introduction. For species with $a_{1}>0$, typically $a_{2}<0$, and $a$ increases up to a maximum at certain $E / N$ and decreases at greater $E / N$. This behavior (called "type B") [5] is ubiquitous for both atomic and polyatomic cations and anions with $m<$ $\sim 400 \mathrm{Da}$ in $\mathrm{N}_{2}$ or air at room temperature, including 13 of 17 protonated and 15 of 17 deprotonated amino acids [54], protonated benzene, and all seven amines studied [55], eight protonated ketones up to decanone and five of their proton-bound dimers [56], all 10 protonated organophosphorus compounds investigated and seven of their dimers [57], and $\mathrm{I}^{-}$and anions of five common explosives and their degradants: 1,3-dinitrobenzene, 1,3,5trinitrobenzene, p-mononitrotoluene, 2,4-dinitrotoluene, and 2,4,6-trinitrotoluene (TNT) [28]. The magnitude of $a_{2} / a_{1}$ for those 72 species spans $>3$ orders of magnitude from $<10^{-6}$ to $>10^{-3} \mathrm{Td}^{-2}$ (Figure 5), but most values are about $10^{-5}$ to $10^{-4} \mathrm{Td}^{-2}$ regardless of the ion mass. The median $a_{2} / a_{1}$ is $-5.5 \times 10^{-5} \mathrm{Td}^{-2}$, for which $a_{\mathrm{R}}=-0.5$ at $E / N \sim 95 \mathrm{Td}$ that is typical for either micromachined or "full-size" FAIMS. Exemplary species close to this median are $(\mathrm{Glu}-\mathrm{H})^{-}$, $(\mathrm{TNT}-\mathrm{H})^{-}($Table 2$)$, and anions of other four explosive traces with $a_{2} / a_{1}=$ $-(5.2-6.0) \times 10^{-5} \mathrm{Td}^{-2}$. Half of the ions have higher $\left|a_{2} / a_{1}\right|$ values and $a_{\mathrm{R}}=-0.5$ is reached at lower $E / N$; for some, e.g., $\mathrm{H}^{+}$(decanone) (Table 2), that occurs already at the lower end of practical FAIMS range $(\sim 60$ to $70 \mathrm{Td}$ ). For most other ions, $\left|a_{2} / a_{1}\right|>10^{-5}$ and $a_{\mathrm{R}}$ reaches -0.5 at $E / N<220 \mathrm{Td}$, i.e., well within the range of Owlstone devices. Rarely, the $a_{2} / a_{1}$ values are so miniscule that $a_{\mathrm{R}}$ remains insignificant at $E / N$ used in current FAIMS systems (Figure 5). For example, for $(\text { Ala }-\mathrm{H})^{-}($Table 2$), a_{\mathrm{R}}$ would reach -0.5 only at $E / N$ $\sim 10^{3} \mathrm{Td}$. As present $a_{1}$ and $a_{2}$ values were fit to FAIMS measurements at $E_{\mathrm{D}} / N \sim 70$ to $120 \mathrm{Td}$, they cannot be used to accurately extrapolate $a(E / N)$ to much stronger fields where terms with higher $n$ become important. Hence, we compute $a_{\mathrm{R}}$ values at higher $E_{\mathrm{D}} / N$ not to maximize $\left|E_{C}\right|$ for specific ions, but to illustrate the $E_{\mathrm{D}} / N$ magnitude at which the optimum waveforms in typical scenarios materially deviate from those derived for $a_{\mathrm{R}}=0$.

The specific $a_{\mathrm{n}}$ and thus $a_{\mathrm{R}}$ at certain $E_{\mathrm{D}}$ for any ion depend on the gas composition, and $\left|a_{2} / a_{1}\right|$ values in some exceed those in $\mathrm{N}_{2}$. For example, the humidity in ambient air (often used in field analyses) modifies $a(E)$. At any water vapor pressure tried [58] $\left(P_{\mathrm{w}}=120\right.$ to 6000 ppm), ions of all four explosives and their degradants measured retain $a_{1}>0$ and $a_{2}<0$, but $\left|a_{2} / a_{1}\right|$ increases at higher $P_{\mathrm{w}}$ up to a maximum of $8.3 \times 10^{-5} \mathrm{Td}^{-2}$ that leads to $a_{\mathrm{R}}<-0.5$ already at $E_{\mathrm{D}}=80 \mathrm{Td}$.

For "type A" ions [5], the $a(E / N)$ curves measured by FAIMS are fit by $a_{1}>0$ and $a_{2}>0$. In $\mathrm{N}_{2}$ or air, this applies primarily to the smallest ions (e.g., $\mathrm{Cl}^{-}$), but also some medium-size ones such as (Pro $-\mathrm{H})^{-}$(Table 2). Though $a_{2} / a_{1}$ values can be quite high and produce substantial $a_{\mathrm{R}}$ even at low $E_{\mathrm{D}} / N$ (for $\mathrm{Cl}^{-}, a_{\mathrm{R}}=1.7$ already at $70 \mathrm{Td}$ ), positive $a_{\mathrm{R}}$ hardly warrant waveform reoptimization, as discussed above. However, $a(E / N)$ functions cannot increase indefinitely: at $E / N \Rightarrow \infty$, the ion/molecule potential always approaches the hardshell limit where $K$ drops [32] at higher $E / N$. Thus, when $a_{1}>0$, the value of $a$ maximizes at finite $E / N$ (exhibiting type $\mathrm{B}$ behavior) and observation of type $\mathrm{A}$ ions is a mere artifact of limited $E / N$ range sampled in FAIMS. (Most type A ions are small because the maxima of $K$ shift to greater $E / N$ for deeper ion/molecule potentials that are more common to smaller and particularly atomic ions where the gas molecule can come close to the charged site.) That type A ions inevitably convert to type B at higher $E / N$ implies that $a_{\mathrm{n}}<0$ for some $n>1$. Though $n$ may equal 3 or greater, the effect on optimum waveform at $E / N$ near or above the maximum $K$ will overall resemble that explored here for type B behavior due to $a_{2}<0$.

\section{Targeted Separations}

As a filtering technique, FAIMS (like quadrupole MS) is mainly useful for targeted analyses, where removal of other species does no harm. In quadrupole MS, the conditions for maximum resolution of targeted analyses (in the selected ion monitoring mode) and global analyses (in the scanning mode) are identical. That is not quite true in FAIMS.

Targeted separations depend on the spread between $d$ and thus $E_{C}$ values of two or more species and not $E_{C}$ of a single ion, as indicated by eq 9 . To optimize $E(t)$ for resolution of analytes $X$ and $Y$, we should replace the coefficients $a_{\mathrm{n}}$ for one ion by $\left(a_{\mathrm{n}, \mathrm{X}}-a_{\mathrm{n}, \mathrm{Y}}\right)$. Then the dependences of optimum waveforms on $a_{\mathrm{R}}$ found above continue to apply, with $a_{\mathrm{R}}$ still given by eq 17 but $a_{2} / a_{1}$ defined as:

$$
a_{2} / a_{1}=\left(a_{2, X}-a_{2, Y}\right) /\left(a_{1, X}-a_{1, Y}\right)
$$

A prototypical isomeric separation in biological analyses is that of leucine and isoleucine amino acids. Those were resolved by FAIMS as deprotonated anions in $\mathrm{N}_{2}$ [59] and protonated cations in 1:1 $\mathrm{He} / \mathrm{N}_{2}$, [4] in both cases just barely. For anions, the experimental $E_{\mathrm{D}} / N$ was $67 \mathrm{Td}$, where $a_{\mathrm{R}}$ equals -0.15 for $(\mathrm{Leu}-\mathrm{H})^{-}$and -0.05 for $(\text { Ile }-\mathrm{H})^{-}$(Table 2). Both values suggest that the best $F(t)$ for this separation is essentially identical to that for $a_{2}=0$. However, the difference between $a(E / N)$ of Ile and Leu anions has $\left\{a_{1}=0.28 \times 10^{-6} \mathrm{Td}^{-2} ; a_{2}=\right.$ $\left.-1.27 \times 10^{-10} \mathrm{Td}^{-4}\right\}$, leading to very high $\left|a_{2} / a_{1}\right|=$ $45 \times 10^{-5} \mathrm{Td}^{-2}$ and $a_{\mathrm{R}}=-2.0$ at same $67 \mathrm{Td}$. Hence this separation can likely be improved using the waveforms optimized for region $\mathrm{L}$.

This situation is not limited to isomers. For the deprotonated hydroxyproline (ProOH) (Table 2) that is 


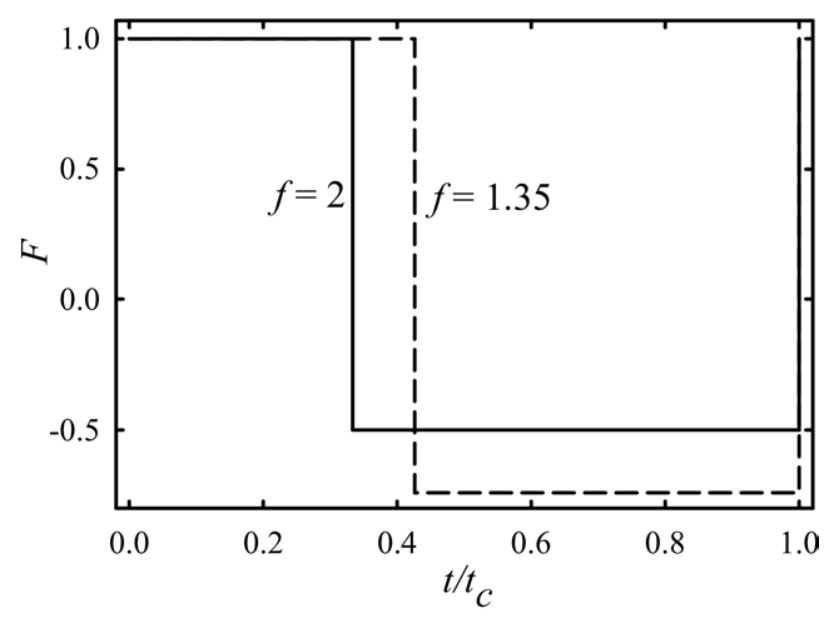

Figure 6. Near-optimum waveforms proposed for use in regions $\mathrm{H}$ (solid line) and L (dashed line); values of $f$ are marked.

isobaric to (Leu $-\mathrm{H})^{-}$, the value of $a_{\mathrm{R}}$ at $67 \mathrm{Td}$ equals -0.01 , and the optimum $E(t)$ is determined solely by the $n=1$ term. However, the differential $a(E / N)$ of $(\mathrm{ProOH}-\mathrm{H})^{-}$and $(\mathrm{Leu}-\mathrm{H})^{-}$has $\left\{a_{1}=0.12 \times 10^{-6}\right.$ $\left.\mathrm{Td}^{-2} ; a_{2}=1.77 \times 10^{-10} \mathrm{Td}^{-4}\right\}$, and $a_{2 /} a_{1}$ is an extreme $\sim 150 \times 10^{-5} \mathrm{Td}^{-2}$ leading to $a_{\mathrm{R}}=6.6$. So, even at this low $E_{\mathrm{D}} / N$, the optimum $F(t)$ is determined almost only by the $n>1$ terms. That is of little consequence here because $a_{\mathrm{R}}>0$, but isobars with similarly large negative $a_{2 /} a_{1}$ certainly exist.

Much greater magnitude of $a_{2} / a_{1}$ by eq 21 compared with $a_{2} / a_{1}$ for either $\mathrm{X}$ or $\mathrm{Y}$ in above cases reflects a lower correlation of $a_{2}$ values for different ions compared to that of $a_{1}$ [44]. Opposite examples exist: the differential $a(E / N)$ of $(\text { Ser }-\mathrm{H})^{-}$and (Leu $\left.-\mathrm{H}\right)^{-}$has $\left\{a_{1}=6.97 \times 10^{-6} \mathrm{Td}^{-2} ; a_{2}=0.08 \times 10^{-10} \mathrm{Td}^{-4}\right\}$, and $a_{2} / a_{1}=0.11 \times 10^{-5} \mathrm{Td}^{-2}$ is much lower than the values for either species (Table 2). However, the median values of $\left|a_{2} / a_{1}\right|$ (in $10^{-5} \mathrm{Td}^{-2}$ ) for 17 amino acids studied [54] and their 136 possible pairs are, respectively, 1.9 versus 4.7 for cations and 1.7 versus 5.6 for anions. The results for subsets of ions and pairs with $a_{2} / a_{1}<0$ are similar: the medians are 1.9 versus 4.6 for cations and 2.1 versus 7.9 for anions. That is, statistically the mean effective $\left|a_{R}\right|$ values for pairs of amino acid ions at any $E / N$ are $\sim 3$ times those for individual ions and $a_{\mathrm{R}} \sim-0.5$ for pairs with $a_{2} / a_{1}<0$ will be reached at $E / N$ lower by a factor of $\sim \sqrt{3}$ : on average $\sim 90 \mathrm{Td}$ typical in standard FAIMS systems versus $\sim 160 \mathrm{Td}$ used at reduced pressure or in miniature chips. Thus, the distinction between optimum waveforms at $a_{\mathrm{R}}=0$ and $\sim-1$ is likely more important in targeted analyses.

\section{Conclusions}

The asymmetric waveforms $E(t)$ that maximize resolving power $(R)$ of FAIMS materially depend on the $a(E / N)$ profile(s) for ion(s) of interest. The optimum $E(t)$ is defined by $E / N$ and ratios of coefficients $a_{\mathrm{n}}$ with the terms of $a(E / N)$ expansion in a power series: truncating to two terms, the key quantity is $a_{\mathrm{R}}=a_{2}(E / N)^{2} / a_{1}$. For positive $a_{\mathrm{R}}$ (when the terms add), the effect is small: $E(t)$ optimized without considering the $a(E / N)$ profile (i.e., for $a_{\mathrm{R}}=0$ ) provide $R$ within $\sim 7 \%$ of the maximum. In this case, one should always maximize the $E(t)$ amplitude, $E_{\mathrm{D}}$, within the power supply or electrical breakdown constraints. With negative $a_{R}$, the second term is subtracted from the first and, at $a_{\mathrm{R}} \sim-1$, the difference that underlies FAIMS separation is not close to either. This produces "sub-optimum" (S) regions at $a_{\mathrm{R}}$ within the $-(0.5$ to 0.9$)$ range, where separation is improved via reducing $E_{\mathrm{D}}$ by up to $\sim 20 \%$ to $30 \%$ from the maximum until $\left|a_{R}\right|$ decreases to the region boundary. The optimum $E(t)$ remain close to those at $a_{\mathrm{R}}=0$ in regions $\mathrm{H}$ on the high $a_{\mathrm{R}}$ side of $\mathrm{S}$, but substantially differ in regions $\mathrm{L}$ on the low $a_{\mathrm{R}}$ side, where using the $E(t)$ optimized at $a_{\mathrm{R}}=0$ reduces $R$ for all three classes by up to 2.2 times. In $L$, the optimum $E(t)$ also depends on $a_{R}$, but $>90 \%$ of maximum $R$ can always be achieved using fixed forms intermediate between those optimum on the L/S boundary and for $a_{R} \Rightarrow \infty$. Thus reoptimization of $E(t)$ for each $a_{\mathrm{R}}$ can in practice be emulated by selecting one of the two forms (Figure 6). In $\mathrm{H}$, we can use $E(t)$ optimized for $a_{\mathrm{R}}=0$ and employed in present FAIMS systems, while the new $E(t)$ found here can produce significant gains in L. Though we included only the first two terms of the $a(E / N)$ expansion, the optimum waveforms are primarily dictated by (constructive or destructive) interference of terms, and not their specific powers. Hence, addition of further terms (which are often quite significant in advanced FAIMS designs using $E / N>100 \mathrm{Td}$ ) will produce similar effects that can be treated using the present framework.

Ions in FAIMS have been grouped into type A where the $a(E / N)$ function increases, type $\mathrm{B}$ where it has a maximum, and type $C$ where it decreases [5]. Analyses of types $\mathrm{A}$ and $\mathrm{C}$ ions fall into the $\mathrm{H}$ region, and new waveforms proposed here for the $\mathrm{L}$ region would be used for type $B$ species that include most ions of explosives in air or $\mathrm{N}_{2}$ over a broad range of humidity. However, all type $\mathrm{A}$ ions convert to type $\mathrm{B}$ at higher $E / N$ values, and thus new waveforms become relevant for species deemed type $A$ as new miniaturized or reduced-pressure FAIMS systems using higher $E / N$ are introduced. The key applications of FAIMS are to targeted analyses that are based not on individual $a(E / N)$ functions, but rather on the spread of these functions that can behave as "type B" even when neither ion does. Hence, new waveforms intended for $\mathrm{L}$ region may improve resolution of specific ions despite $R$ for each maximized by existing $E(t)$.

Though presently optimized waveforms maximize FAIMS specificity for an ion or ion pair, different $E(t)$ may be desired for other reasons. In particular, a $F(t)$ that sort ions by $a_{\mathrm{n}}$ values for $n>1$ without regard to $a_{1}$ may enable higher-order differential (HOD) IMS [44] analyses that should be substantially orthogonal to FAIMS based on whole $a(E / N)$. As optimum $E(t)$ for 
separation of ion pairs depend on their differential $a_{\mathrm{n}}$ values, the best forms for resolution of three or more ions will generally deviate from those for each pairwise combination; their optimization remains to be explored. In contrast, absolute ion mobilities that underlie conventional IMS depend on $E$ weakly or not at all within the measurement accuracy, and ions with equal $K$ at some $E$ are unlikely to be resolved at any practical $E$. The possibility to tailor analyses by modifying $F(t)$ is one manifestation of the unique flexibility of differential IMS.

\section{Acknowledgments}

The authors thank Drs. Keqi Tang, Aleksey Tolmachev, and Robert Ewing (PNNL) for discussions of optimization and analytical use of FAIMS. This research has been supported by PNNL Initiative for Explosives Detection and NIH National Center for Research Resources (RR 18,522) located in the Environmental Molecular Sciences Laboratory, a national scientific user facility at PNNL sponsored by the U.S. Department of Energy Office of Biological and Environmental Research. PNNL is operated for the DOE by Battelle under Contract DE-AC05-76RLO 1830.

\section{References}

1. Buryakov, I. A.; Krylov, E. V.; Nazarov, E. G.; Rasulev, U. K. A New Method of Separation of Multi-Atomic Ions by Mobility at Atmospheric Pressure Using a High-Frequency Amplitude-Asymmetric Strong Electric Field. Int. J. Mass Spectrom. Ion Processes 1993, 128, 143-148.

2. Purves, R. W.; Guevremont, R. Electrospray Ionization High-Field Asymmetric Waveform Ion Mobility Spectrometry-Mass Spectrometry. Anal. Chem. 1999, 71, 2346-2357.

3. Miller, R. A.; Eiceman, G. A.; Nazarov, E. G.; King, A. T. A Novel Micromachined High-Field Asymmetric Waveform-Ion Mobility Spectrometer. Sens. Actuators B 2000, 67, 300-306.

4. Shvartsburg, A. A.; Li, F.; Tang, K.; Smith, R. D. High-Resolution Field Asymmetric Waveform Ion Mobility Spectrometry Using New Planar Geometry Analyzers. Anal. Chem. 2006, 78, 3706-3714.

5. Guevremont, R. High-Field Asymmetric Waveform Ion Mobility Spectrometry: A New Tool for Mass Spectrometry. J. Chromatogr. A 2004, 1058, 3-19.

6. Gabryelski, W.; Froese, K. L. Characterization of Naphthenic Acids by Electrospray Ionization High-Field Asymmetric Waveform Ion Mobility Spectrometry Mass Spectrometry. Anal. Chem. 2003, 75, 4612-4623.

7. Eiceman, G. A.; Krylov, E. V.; Tadjikov, B.; Ewing, R. G.; Nazarov, E. G.; Miller, R. A. Differential Mobility Spectrometry of Chlorocarbons with a Micro-Fabricated Drift Tube. Analyst 2004, 129, 297-304.

8. Gabryelski, W.; Wu, F.; Froese, K. L. Comparison of High-Field Asymmetric Waveform Ion Mobility Spectrometry with GC Methods in Analysis of Haloacetic Acids in Drinking Water. Anal. Chem. 2003, 75, $2478-2486$.

9. Sander, L. C.; Sharpless, K. E.; Satterfield, M. B.; Ihara, T.; Phinney, K. W.; Yen, J. H.; Wise, S. A.; Gay, M. L.; Lam, J. W.; McCooeye, M.; Gardner, G.; Fraser, C.; Sturgeon, R.; Roman, M. Determination of Ephedrine Alkaloids in Dietary Supplement Standard Reference Materials. Anal. Chem. 2005, 77, 3101-3112.

10. Liu, X.; Zhao, Y. Y.; Chan, K.; Hrudey, S. E.; Li, X. F.; Li, J. J. Analysis of Nitrosamines by Capillary Electrospray-High-Field Asymmetric Waveform Ion Mobility Spectrometry-MS with Programmed Compensation Voltage. Electrophoresis 2007, 28, 1327-1334.

11. Schmidt, H.; Tadjimukhamedov, F.; Mohrenz, I. V.; Smith, G. B.; Eiceman, G. A. Microfabricated Differential Mobility Spectrometry with Pyrolysis Gas Chromatography for Chemical Characterization of Bacteria. Anal. Chem. 2004, 76, 5208-5217.

12. Shnayderman, M.; Mansfield, B.; Yip, P.; Clark, H. A.; Krebs, M. D.; Cohen, S. J.; Zeskind, J. E.; Ryan, E. T.; Dorkin, H. L.; Callahan, M. V.; Stair, T. O.; Gelfand, J. A.; Gill, C. J.; Hitt, B.; Davis, C. E. Species-Specific Bacterial Identification Using Differential Mobility Spectrometry and Bioinformatics Pattern Recognition. Anal. Chem. 2005, 77, 5930-5937.

13. Lu, Y.; Harrington, P. B. Forensic Applications of Gas ChromatographyDifferential Mobility Spectrometry with Two-Way Classification of Ignitable Liquids from Fire Debris. Anal. Chem. 2007, 79, 6752-6759.

14. Guevremont, R.; Barnett, D. A.; Purves, R. W.; Vandermey, J. Analysis of a Tryptic Digest of Pig Hemoglobin Using ESI-FAIMS-MS. Anal. Chem. 2000, 72, 4577-4584.
15. Venne, K.; Bonneil, E.; Eng, K.; Thibault, P. Improvement in Peptide Detection for Proteomics Analyses Using NanoLC-MS and High-Field Asymmetry Waveform Ion Mobility Mass Spectrometry. Anal. Chem. 2005, 77, 2176-2186.

16. Tang, K.; Li, F.; Shvartsburg, A. A.; Strittmatter, E. F.; Smith, R. D. Two-Dimensional Gas-Phase Separations Coupled to Mass Spectrometry for Analysis of Complex Mixtures. Anal. Chem. 2005, 77, 6381-6388.

17. Li, J.; Purves, R. W.; Richards, J. C. Coupling Capillary Electrophoresis and High-Field Asymmetric Waveform Ion Mobility SpectrometryMass Spectrometry for the Analysis of Complex Lipopolysaccharides. Anal. Chem. 2004, 76, 4676-4683.

18. Kapron, J.; Wu, J.; Mauriala, T.; Clark, P.; Purves, R. W.; Bateman, K. P. Simultaneous Analysis of Prostanoids Using Liquid Chromatography/ High-Field Asymmetric Waveform Ion Mobility Spectrometry/Tandem Mass Spectrometry. Rapid Commun. Mass Spectrom. 2006, 20, 1504-1510.

19. Hatsis, P.; Brockman, A. H.; Wu, J. T. Evaluation of High-Field Asymmetric Waveform Ion Mobility Spectrometry Coupled to Nanoelectrospray Ionization for Bioanalysis in Drug Discovery. Rapid Commun. Mass Spectrom. 2007, 21, 2295-2300.

20. Mie, A.; Jornten-Karlsson, M.; Axelsson, B. O.; Ray, A.; Reimann, C. T. Enantiomer Separation of Amino Acids by Complexation with Chiral Reference Compounds and High-Field Asymmetric Waveform Ion Mobility Spectrometry: Preliminary Results and Possible Limitations. Anal. Chem. 2007, 79, 2850-2858.

21. Purves, R. W.; Barnett, D. A.; Ells, B.; Guevremont, R. Elongated Conformers of Charge States +11 to +15 of Bovine Ubiquitin Studied Using ESI-FAIMS-MS. J. Am. Soc. Mass Spectrom. 2001, 12, 894-901.

22. Borysik, A. J. H.; Read, P.; Little, D. R.; Bateman, R. H.; Radford, S. E. Ashcroft, A. E. Separation of $\beta_{2}$-microglobulin Conformers by HighField Asymmetric Waveform Ion Mobility Spectrometry (FAIMS) Coupled to Electrospray Ionization Mass Spectrometry. Rapid Commun. Mass Spectrom. 2004, 18, 2229-2234.

23. Robinson, E. W.; Leib, R. D.; Willams, E. R. The Role of Conformation on Electron Capture Dissociation of Ubiquitin. J. Am. Soc. Mass Spectrom. 2006, 17, 1470-1480.

24. Shvartsburg, A. A.; Bryskiewicz, T.; Purves, R. W.; Tang, K.; Guevremont, R.; Smith, R. D. Field Asymmetric Waveform Ion Mobility Spectrometry Studies of Proteins: Dipole Alignment in Ion Mobility Spectrometry? J. Phys. Chem. B 2006, 110, 21966-21980.

25. Shvartsburg, A. A.; Li, F.; Tang, K.; Smith, R. D. Characterizing the Structures and Folding of Free Proteins Using 2-D Gas-Phase Separations: Observation of Multiple Unfolded Conformers. Anal. Chem. 2006, 78, 3304-3315; ibid 8575.

26. Buryakov, I. A.; Kolomiets, Y. N.; Luppu, B. V. Detection of Explosive Vapors in the Air Using an Ion Drift Nonlinearity Spectrometer. J. Anal. Chem. 2001, 56, 336-340.

27. Buryakov, I. A.; Kolomiets, Y. N. Rapid Determination of Explosives and Narcotics Using a Multicapillary-Column Gas Chromatograph and an Ion-Mobility Spectrometer. J. Anal. Chem. 2003, 58, 944-950.

28. Buryakov, I. A. Qualitative Analysis of Trace Constituents by Ion Mobility Increment Spectrometer. Talanta 2003, 61, 369-375.

29. Buryakov, I. A. Express Analysis of Explosives, Chemical Warfare Agents and Drugs with Multicapillary Column Gas Chromatography and Ion Mobility Increment Spectrometry. J. Chromatogr. B 2004, 800, 75-82.

30. Eiceman, G. A.; Krylov, E.; Krylova, N.; Nazarov, E. G.; Miller, R. A. Separation of Ions from Explosives in Differential Mobility Spectrometry by Vapor-Modified Drift Gas. Anal. Chem. 2004, 76, 4937-4944.

31. Buryakov, I. A.; Kolomietz, Y. N.; Bolotov, A. V.; Vasin, A. I.; Vlasov, Y. N. Registration of Lewisite Vapors in Air Using an Ion Mobility Spectrometer. J. Anal. Chem. 2002, 57, 606-610.

32. McDaniel, E. W.; Mason, E. A. Transport Properties of Ions in Gases; Wiley: NY. 1988.

33. Krylov, E. V.; Nazarov, E. G.; Miller, R. A. Differential Mobility Spectrometer: Model of Operation. Int. J. Mass Spectrom. 2007, 266 $76-85$.

34. Eiceman, G. A.; Karpas, Z. Ion Mobility Spectrometry; CRC: Boca Raton, FL, 2005.

35. Akridge, G. R.; Ellis, H. W.; Pai, R. Y.; McDaniel, E. W. Mobilities of Li ${ }^{+}$ Ions in $\mathrm{He}, \mathrm{Ne}$, and $\mathrm{Ar}$ and of $\mathrm{Na}^{+}$Ions in $\mathrm{He}, \mathrm{Ne}, \mathrm{Ar}$, and $\mathrm{CO}_{2}$. J. Chem. Phys. 1975, 62, 4578-4579.

36. Iinuma, K.; Imai, M.; Satoh, Y.; Takebe, M. Mobilities of $\mathrm{Li}^{+}$Ions in $\mathrm{HCl}$, $\mathrm{HBr}$, and $\mathrm{HI}$ at Room Temperature. J. Chem. Phys. 1988, 89, 7035-7036.

37. Barnett, D. A.; Ells, B.; Guevremont, R.; Purves, R. W.; Viehland, L. A Evaluation of Carrier Gases for Use in High-Field Asymmetric Waveform Ion Mobility Spectrometry. J. Am. Soc. Mass Spectrom. 2000, 11, 1125-1133.

38. Ruotolo, B. T.; McLean, J. A.; Gillig, K. J.; Russell, D. H. The Influence and Utility of Varying Field Strength for the Separation of Tryptic Peptides by Ion Mobility-Mass Spectrometry. J. Am. Soc. Mass Spectrom. 2005, 16, 158-165.

39. Gorshkov, M. P. Method for Analysis of Additives to Gases. USSR Inventor's Certificate No. 966583; 1982

40. Buryakov, I. A.; Krylov, E. V.; Soldatov, V. P. Method for Analysis of Additives to Gases. USSR Inventor's Certificate No. 1337934; 1987.

41. Buryakov, I. A.; Krylov, E. V.; Makas, A. L.; Nazarov, E. G.; Pervukhin, V. V.; Rasulev, U. K. Ion Division by their Mobility in High-Tension Alternating Electric Field. Tech. Phys. Lett. 1991, 17, 412. 
42. Krylov, E. V. Comparison of the Planar and Coaxial Field Asymmetrical Waveform Ion Mobility Spectrometer. Int. J. Mass Spectrom. 2003, 225, $39-51$

43. Elistratov, A. A.; Shibkov, S. V. A Model of Nonlinear Ion Drift Spectrometry for Gas Detectors with Separating Chamber of Cylindrical Geometry. Tech. Phys. Lett. 2004, 30, 183-185.

44. Shvartsburg, A. A.; Mashkevich, S. V.; Smith, R. D. Feasibility of Higher-Order Differential Ion Mobility Separations Using New Asymmetric Waveforms. J. Phys. Chem. A 2006, 110, 2663-2673.

45. Krylov, E. V. Pulses of Special Shapes Formed on a Capacitive Load. Inst. Exp. Tech. 1997, 40, 628-631.

46. Shvartsburg, A. A.; Tang, K.; Smith, R. D. Optimization of the Design and Operation of FAIMS Analyzers. J. Am. Soc. Mass Spectrom. 2005, 16, 2-12.

47. Shvartsburg, A. A.; Tang, K.; Smith, R. D. Modeling the Resolution and Sensitivity of FAIMS Analyses. J. Am. Soc. Mass Spectrom. 2004, 15, 1487-1498.

48. Boyle, B.; Koehl, A.; Parris, R.; Ruiz-Alonso, D; Rush, M.; Wilks, A. A MEMS Fabricated Device for Field Asymmetric Ion Mobility Spectrometry. Proceedings of the $59^{\text {th }}$ Pittcon Conference, New Orleans, LA $(03 / 2008)$

49. Nazarov, E. G.; Coy, S. L.; Krylov, E. V.; Miller, R. A.; Eiceman, G. A. Pressure Effects in Differential Mobility Spectrometry. Anal. Chem. 2006, 78, 7697-7706.

50. Papanastasiou, D.; Wollnik, H.; Rico, G.; Tadjimukhamedov, F.; Mueller, W.; Eiceman, G. A. Differential Mobility Separation of Ions Using a Rectangular Asymmetric Waveform. J. Phys. Chem. A 2008, 112, 3638-3645.

51. Buryakov, I. A.; Krylov, E. V.; Soldatov, V. P. Drift Spectrometer for Trace Detection of Substances in Gases. USSR Inventor's Certificate No. 1412447; 1989.
52. Viehland, L. A.; Guevremont, R.; Purves, R. W.; Barnett, D. A. Comparison of High-Field Ion Mobility Obtained from Drift Tubes and a FAIMS Apparatus. Int. J. Mass Spectrom. 2000, 197, 123-130.

53. Meek, J. M.; Craggs, J. D. Electrical Breakdown of Gases; Wiley: New York, 1978.

54. Guevremont, R. Barnett, D. A.; Purves, R. W.; Viehland, L. A. Calculation of Ion Mobilities from Electrospray Ionization High-Field Asymmetric Waveform Ion Mobility Spectrometry Mass Spectrometry. J. Chem. Phys. 2001, 114, 10270-10277.

55. Buryakov, I. A. Determination of Kinetic Transport Coefficients for Ions in Air as Functions of Electric Field and Temperature. Tech. Phys. 2004, 49, 967-972.

56. Krylov, E.; Nazarov, E. G.; Miller, R. A.; Tadjikov, B.; Eiceman, G. A Field Dependence of Mobilities for Gas-Phase-Protonated Monomers and Proton-Bound Dimers of Ketones by Planar Field Asymmetric Waveform Ion Mobility Spectrometer (PFAIMS). J. Phys. Chem. A 2002, 106, 5437-5444.

57. Krylova, N.; Krylov, E.; Eiceman, G. A.; Stone, J. A. Effect of Moisture on the Field Dependence of Mobility for Gas-Phase Ions of Organophosphorus Compounds at Atmospheric Pressure with Field Asymmetric Ion Mobility Spectrometry. J. Phys. Chem. A 2003, 107, 3648-3654.

58. Buryakov, I. A Effect of the Water Vapor Density on the Field Dependence of the Ion Mobility Increment for Nitro Compounds in Air. Tech. Phys. Lett. 2007, 33, 861-864.

59. Barnett, D. A.; Ells, B.; Guevremont, R.; Purves, R. W. Separation of Leucine and Isoleucine by Electrospray Ionization High-Field Asymmetric Waveform Ion Mobility Spectrometry-Mass Spectrometry. J. Am. Soc. Mass Spectrom. 1999, 10, 1279-1284. 